\title{
An investigative review on the current role and outcomes of salvage radical cystectomy
}

\author{
Antonio Cicione, Riccardo Lombardo, Olivia Alessandra Voglino, Andrea Tubaro, Cosimo De Nunzio \\ Department of Urology, Sant'Andrea Hospital, Sapienza University of Rome, Rome 00189, Italy.
}

Correspondence to: Dr. Antonio Cicione, Department of Urology, Sant'Andrea Hospital, Sapienza University of Rome, Via di Grottarossa 1085, Rome 00189, Italy. E-mail: acicione@libero.it

How to cite this article: Cicione A, Lombardo R, Voglino OA, Tubaro A, De Nunzio C. An investigative review on the current role and outcomes of salvage radical cystectomy. Mini-invasive Surg 2021;5:47. https://dx.doi.org/10.20517/2574-1225.2021.52

Received: 20 Apr 2021 First Decision: 10 May 2021 Revised: 12 May 2021 Accepted: 17 May 2021 Published: 8 Oct 2021

Academic Editor: Riccardo Autorino Copy Editor: Xi-Jun Chen Production Editor: Xi-Jun Chen

\begin{abstract}
Salvage radical cystectomy (SRC) is currently performed after failure of a trimodal treatment (TMT) for muscle invasive bladder cancer (MIBC) and also as a palliative surgery to manage bladder cancer-related symptoms. We reviewed the available literature to assess the current outcomes of SRC. A comprehensive research of the Medline and Embase databases was carried out by following the Preferred Items for Systematic Reviews and MetaAnalysis. Bladder cancer, radiotherapy, salvage, and cystectomy were the main keywords used in the research. Due to the lack of studies, no time restriction was applied, however only English language and only studies using Clavien-Dindo Grade (CCS) to report complications were considered. Overall, 285 studies were identified, of which 41 studies were considered eligible for the purpose of this review. No comparative studies were found between TMT plus SRC and immediate radical cystectomy. Thirteen studies reported oncological outcomes after TMT. The five-year mean disease free survival rate of patients who underwent SRC after TMT was reported to be about 50\% and the 5 -year OS rate was between 33\% and 48\%. Three studies including fewer than 20 patients performed SRC with palliative purpose. Although no perioperative death occurred, patients were highly selected. Overall, 4 studies graded surgery-related complications by CCS. The rate of major complications, defined as CCS $\geq 3$, was reported to be between $16 \%$ and $32 \%$, most of them being gastrointestinal complications. SRC still preserves a role in the management of MIBC, being part of TMT and palliative care in highly selected patients. However, this surgery is at higher risk of complications and is associated with incontinent urinary diversion, thus an accurate discussion during patient counseling is advisable.
\end{abstract}


Keywords: Salvage radical cystectomy, bladder cancer, radiotherapy, hematuria

\section{INTRODUCTION}

Nowadays, the improvements in medical, surgical, and anesthetic techniques have dramatically reduced the morbidity and mortality associated with radical cystectomy (RC), but it is still considered a major surgery with a $0.7 \%-42 \%$ risk of developing high-grade complications (defined as Clavien-Dindo Grade $\geq 3$ ) and $0.4 \%-7 \%$ mortality rate ${ }^{[1]}$.

$\mathrm{RC}$ is the standard treatment for muscle invasive bladder cancer (MIBC) recommended for T2-4a, NoNxMo MIBC, in the case of T1 bladder cancer not responsive to BCG treatment or not controllable by $\mathrm{TURB}^{[2]}$. In addition to the surgical skill required to perform RC, one of the challenges regarding this surgery is related to the patient's medical condition. Surgery is generally performed in frail elderly patients, with several comorbidities, intractable gross hematuria and anemia, and some of them (about 10\%-15\%) are metastatic $^{[2]}$.

The term "salvage radical cystectomy" (SRC) initially referred to RC performed after bladder radiotherapy and implied an unfavorable meaning for the more elevated skill required to accomplish the procedure as well as its higher morbidity and mortality rate. Nowadays, SRC term is largely used when the bladder is removed in patients affected of MIBC who previously underwent unsuccessful initial trimodal treatment (TMT) or when RC is carried out for a purely palliative purpose aimed at treating only fatal disease-related complications and symptoms without a true oncologic intent.

We performed a literature review with the aim of summarizing the current role of salvage radical cystectomy in those two clinical settings of MIBC, after a failed initial treatment or as a palliative surgery.

\section{METHODS}

In January 2021, a literature research on PubMed/Medline, Scopus, and Google Scholar databases was performed by using the following keywords: bladder cancer, muscle invasive bladder cancer, bladder preservation, radiotherapy, pelvic irradiation, and salvage cystectomy. The title and the abstract of the retrieved studies were assessed for their relevance and, subsequently, their reference lists were screened to identify further studies. No time limit was applied to the research strategy, however English language restriction was used and no abstracts were included. In particular, two authors (Cicione A and Lombardo R) selected studies which included patients affected by MIBC who underwent salvage cystectomy as a subsequent treatment for supplementary control of disease and studies where RC was carried out only for a symptom-control purpose. Moreover, only studies using the Clavien-Dindo Classification System ${ }^{[3]}$ were used to assess surgery complications of SRC.

The Preferred Reporting Items for Systematic Reviews and Meta-Analyses (PRISMA) statement guidelines were respected in the preparation of this scoping review ${ }^{[4]}[$ Figure 1].

\section{RESULTS}

\section{Salvage radical cystectomy after trimodal therapy: oncological outcomes}

Most of the retrieved studies reporting survival rates after SRC referred to cystectomy performed after preserving bladder treatment for MIBC [Table 1 $]^{[5-18]}$. Moreover, there are no completed randomized trials comparing the oncological outcomes of preserving bladder treatment with $\mathrm{RC}^{[2]}$, whereby the current oncological benefit of SRC after a bladder preserving treatment is based mainly on surgical series. At 

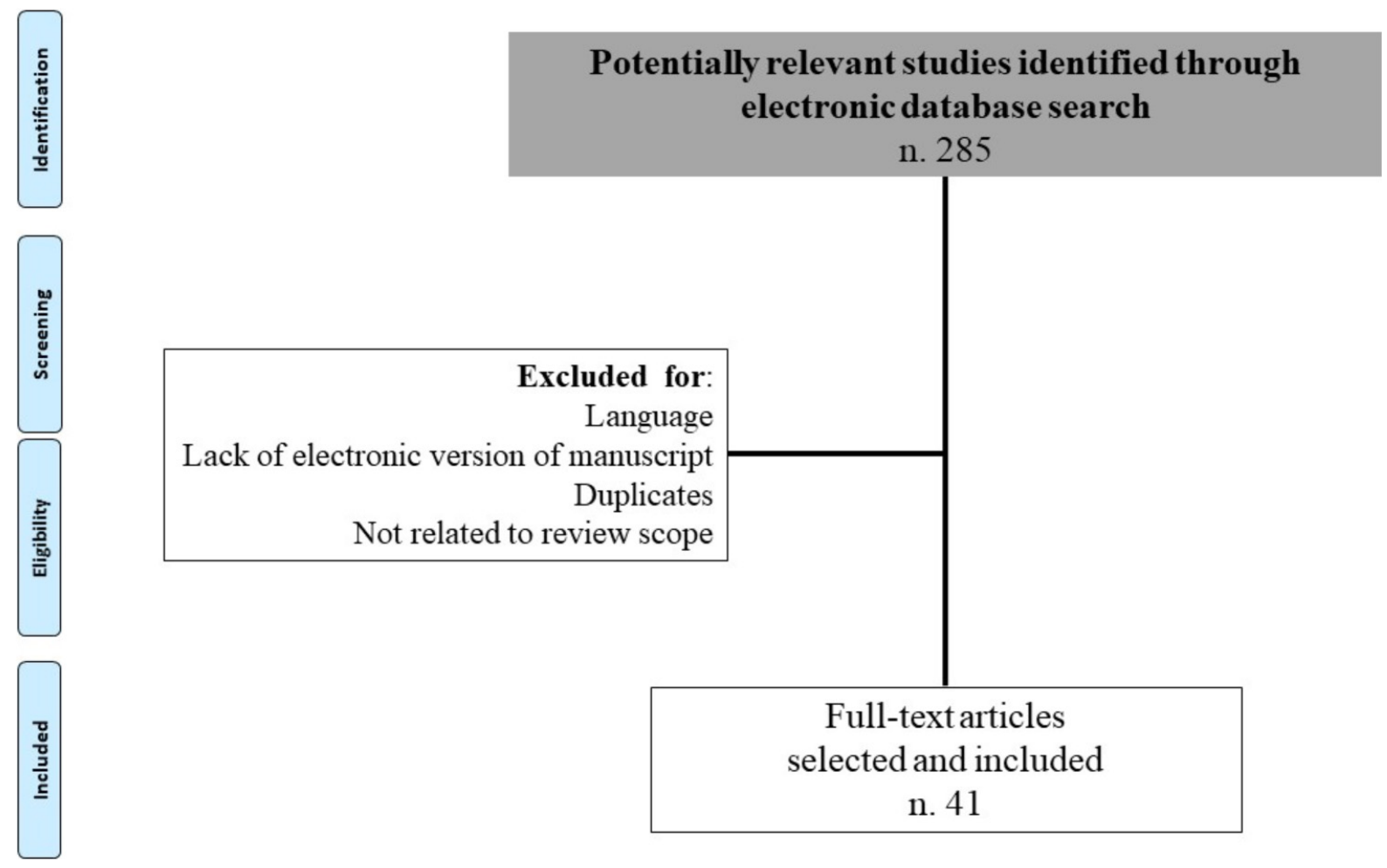

Figure 1. Flow diagram of the literature research.

present, preserving bladder treatment is proposed to patients who refuse or are unfit for RC. The current clinical guidelines of the most popular oncological and urological societies [Table 2] suggest a bladderpreserving treatment known as "trimodality" or "trimodal treatment" to highly selected patients. The ideal patient is affected by an early stage MIBC without limpho-vascular invasion or distant metastases, in the absence of multifocal carcinoma in situ and hydronephrosis with a good bladder function and compliance for a long and close follow-up. The TMT protocol consists of preliminary extensive TURB aimed to remove all the visible tumor and allow a maximal focused radiation on the smallest tumor volume. Rödel et al. ${ }^{[19]}$ showed that the extensiveness of TURB is the key component for any successful bladder-preservation strategy, and it was the only independent prognostic factor for long-term survival in their MIBCs series. Furthermore, the optimal radiation technique and dose have not yet been standardized, but two main protocols are used: split and continuous ${ }^{[20]}$. The first one includes bladder radiation with at least 40-45 Gy to the pelvis and concurrent radiosensitizing chemotherapy followed by an additional radiation boost to the bladder (20-25 Gy) if a complete response is documented on repeat biopsy ${ }^{[21]}$. The latter consists of full dose RT (64-66 Gy) with concurrent chemotherapy after maximal TURB ${ }^{[19]}$. Despite the controversies on the optimal RT protocols, the inferiority of RT alone compared to RT plus chemotherapy has been well established $^{[2]}$. Thus, SRC in TMT setting is reserved for those patients who do not respond to treatment (immediate cystectomy) or develop an invasive recurrence during follow-up (delayed cystectomy).

The first report on SRC was published in 1964 and reported discouraging results with three out of four patients dying due to sepsis. However, further series have been published over the years [Table 1]. One of the largest series included 159 patients initially affected by T2-T4 NxMo MIBC that was managed by $\mathrm{TMT}^{[11]}$. All patients had a good performance status (EGOG score of 0-3) and cisplatin-based chemotherapy was administered. Over a mean follow-up of 11 years, 24\% of patients required SRC after 12 months from initial treatment. After SRC, the median overall survival (OS) was 15 months. No significative difference in 
Table 1. Studies reporting survival outcomes after SRC following trimodal treatment for MIBC

\begin{tabular}{|c|c|c|c|c|}
\hline Ref. & Median age & $\begin{array}{l}\text { Follow } \\
\text { up }\end{array}$ & $\begin{array}{l}\text { SRC patients } \\
(n)\end{array}$ & Oncological outcomes \\
\hline Eswara et al. ${ }^{[5]}$ & $\begin{array}{l}69.4 \\
(27.5-88.9)\end{array}$ & 12 years & 102 & $\begin{array}{l}\text { Disease-free survival rates in the immediate and delayed groups was } \\
38 \% \text { and } 61 \% \text {, respectively, at } 10 \text { years }(P<0.05) \text { with an overall } 10- \\
\text { year disease-free survival rate of } 48 \% \text { for the entire cohort }\end{array}$ \\
\hline George et al. ${ }^{[6]}$ & - & $\begin{array}{l}48.5 \\
\text { months }\end{array}$ & 11 & $\begin{array}{l}7 \text { patients died of disease, } 2 \text { died of other cause at } 27 \text { and } 53 \text { months, } 1 \\
\text { was alive with distant metastases, and } 1 \text { was alive with no evidence of } \\
\text { disease }\end{array}$ \\
\hline Cooke et al. ${ }^{[11]}$ & $65(41-75)$ & 11 years & 38 & $\begin{array}{l}\text { The median time to cystectomy after the primary treatment was } 12 \\
\text { months (range } 56 \text { days to } 10 \text { years). The median survival after } \\
\text { cystectomy was } 15 \text { months ( } 95 \% \mathrm{Cl}: 9-23 \text { months) }\end{array}$ \\
\hline Nieuwenhuijzen et al. ${ }^{[12]}$ & - & - & 27 & $\begin{array}{l}\text { The 3- and 5-year survival probability after cystectomy was } 46 \% \\
(95 \% \mathrm{Cl}: 26-65) \text { and } 33 \%(11-54)\end{array}$ \\
\hline Bochner et al. ${ }^{[13]}$ & - & - & 13 & $\begin{array}{l}\text { After a median follow up of } 28 \text { months, } 15 \text { patients (82\%) were without } \\
\text { evidence of disease }\end{array}$ \\
\hline Crawford et al. ${ }^{[14]}$ & - & - & 34 & $\begin{array}{l}\text { About } 50 \% \text { of patients died for disease progression with a mean survival } \\
\text { time of } 14.5 \text { months }\end{array}$ \\
\hline Freiha et al. ${ }^{[15]}$ & - & - & 40 & $45 \%$ patients alive after 5 years \\
\hline Swanson et al. ${ }^{[16]}$ & $63(41-79)$ & - & 62 & $\begin{array}{l}14.5 \text { months was the median time from the initial diagnosis of bladder } \\
\text { cancer to cystectomy } \\
5 \text {-year survival rate after cystectomy for the whole group was } 43.2 \%\end{array}$ \\
\hline Abratt et al. ${ }^{[17]}$ & $62(36-82)$ & - & 46 & $\begin{array}{l}\text { SRC was need after a mean of } 11 \text { months after radiotherapy. The overall } \\
5 \text {-year survival rate was } 43 \% \text { while it was worse }(7 \%) \text { in case of higher } \\
\text { grade and stage }\end{array}$ \\
\hline Nurmi et al. ${ }^{[18]}$ & $61(32-74)$ & - & 20 & $\begin{array}{l}\text { Intractable voiding symptoms were also reason for SRC. The overall 5- } \\
\text { year survival rate after the operation was } 61 \%\end{array}$ \\
\hline Linell et al. ${ }^{[7]}$ & $66(52-75)$ & - & 19 & $\begin{array}{l}\text { SRC performed both for tumour recurrence and/or bladder symptoms } \\
\text { The 5-year survival rate was } 5 \%\end{array}$ \\
\hline Konnak et al. ${ }^{[8]}$ & $65(50-82)$ & - & 18 & $\begin{array}{l}\text { Interval between RT and SRC ranged between } 6 \text { months }-12 \text { years, mean } \\
2.5 \text { years } \\
\text { The overall crude } 5 \text {-year survival from the time of cystectomy was } 50 \%\end{array}$ \\
\hline Smith et al. ${ }^{[9]}$ & - & - & 80 & $\begin{array}{l}\text { The over-all } 5 \text {-year survival rate was } 37 \% \text { while the postoperative } \\
\text { hospital mortality rate was } 5 \%\end{array}$ \\
\hline Kulkarni et al. ${ }^{[10]}$ & $71(37-95)$ & $\begin{array}{l}4.51 \\
\text { years }\end{array}$ & 6 & $\begin{array}{l}\text { No significative difference in terms of } 5 \text {-years DFS between radical } \\
\text { cystectomy and TMT (respectively, } 73.2 \% \text { vs. } 76.6 \% \text { ) was computed. } \\
\text { SRC was performed in } 6(10.7 \%) \text { of } 56 \text { patients who received TMT }\end{array}$ \\
\hline
\end{tabular}

SRC: Salvage radical cystectomy; MIBC: muscle invasive bladder cancer; DFS: disease free survival; TMT: trimodal treatment.

terms of survival was found for patients receiving SRC or not ${ }^{[11]}$.

Eswara et al.${ }^{[5]}$ retrospectively analyzed clinical data of 348 patients undergoing TMT with extensive TURB, cisplatin-based chemotherapy, and almost 40 Gy radiotherapy. Patient's features were similar to a previous study by Cooke et al. ${ }^{[1]}$ except for the presence of hydronephrosis that was considered an exclusion criterion for trimodal treatment. On overage, SRC was carried out no more than 10.3 months after the last dose of chemotherapy. The 10-year disease free survival rate (DFS) from SRC was $48 \%$, which significatively improved (up to $61 \%$ ) when the surgery was delayed compared to conservative treatment.

Interestingly, Schuettfort et al..$^{[2]}$ recently used a pooled analysis method to assess the efficacy of trimodal treatment. They reviewed the available literature and identified 73 studies including 9110 patients. The analysis showed that SRC was necessary in $19.2 \%$ of cases and 5- and 10-year DFS rates were, respectively, 54.3\% (95\%CI: 48.6-60.1) and 45.6\% (95\%CI: 41.6-49.6). 
Table 2. Current guidelines on bladder preserving approaches for MIBC

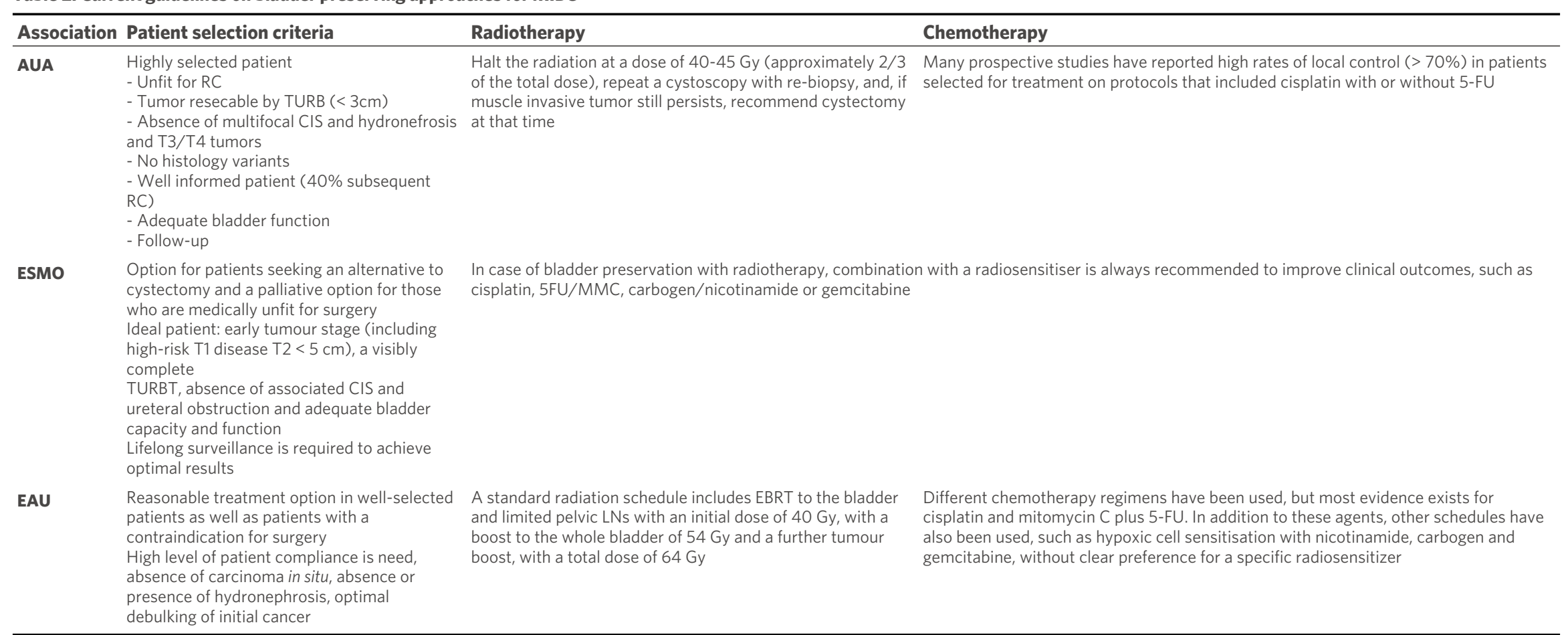

AUA: American Urological Association; ESMO: European Society for Medical Oncology; EAU: European Association of Urology; MIBC: muscle invasive bladder cancer; RC: radical cystectomy

Thus, 10\%-30\% of patients will require SRC after initial curative TMT with a mean 5-year DFS of 50\% and 5-year OS rate of 33\%-48\%. However, those findings may be biased, hypothesizing that all patients requiring SRC were fit for surgery and studies included only patients with $\geq$ T2 NoMo bladder cancer. In patients undergoing RC at primary MIBC diagnosis, Stein et al. ${ }^{[23]}$ showed an OS at 5 and 10 years of $78 \%$ and $56 \%$, respectively, in the presence of organ confined disease with no lymph node involvement. Those rates were dramatically reduced in the presence of extravesical disease extension $(5$-year OS = 55\%; 10 -year OS $=27 \%)$ and lymph nodes involvement ( 5 -year OS $=31 \%$; 10 -year OS $=23 \%)$.

However, the rate of disease-free survival after SRC is higher than in the absence of treatment. Martini et al. ${ }^{[24]}$ evaluated the natural history of MIBC in the absence of treatment by analyzing 64 patients $>79$ years old affected by T2-T4 No high-grade bladder cancer who did not receive any treatment. They found a 
5-year OS of 5\% (95\%CI: $1 \%-12 \%$ ). Furthermore, the median time to death from any cause was 9 months. As predictable, on multivariable analyses, after adjusting for age at diagnosis, sex, clinical stage, and tumor stage, untreated patients had a higher risk of death from any cause [hazard ratio $(\mathrm{HR})=2.63$; 95\%CI: 1.65 4.19; $P<0.001]$, progression to distant metastasis $(\mathrm{HR}=2.40 ; 95 \% \mathrm{CI}: 1.28-4.51 ; P=0.006)$, and cancer specific mortality (HR $=2.02$; 95\% CI: 1.24-3.30; $P=0.005)$.

Overall, between $10 \%$ and $15 \%$ of patients are already metastatic at diagnosis with a median survival rarely exceeding 3-6 months before the development of effective chemotherapy ${ }^{[2]}$. Mak et al.$^{[2]]}$ reported the rate of metastatic disease among 468 patients treated with TMT, which ranged from $32 \%$ to $35 \%$. However, no studies on SRC with curative intent in this stage of disease were retrieved except for a palliative purpose.

Thus, we found that up to $30 \%$ of patients treated with primary TMT with a curative intent subsequently required SRC after 1 year of TMT. Although no comparative studies with RC are still available, SRC with a curative intent seems to be feasible with acceptable oncological outcomes. Moreover, the recent introduction of immunotherapy in the chemotherapeutic armamentarium encourages further assessing approaches that preserve the bladder.

\section{Salvage radical cystectomy as palliative care: surgical outcomes}

Bladder cancer is related to a significant morbidity for its debilitating symptoms. Among them, hematuria is the most common presenting symptom occurring in approximately $85 \%$ of diagnosed cases. Beyond the tumor mass, side effects of radiation or upper urinary tract neoplasms may be further reasons for bleeding. Sometimes hematuria may be difficult to control, uncurable by irrigation or hemostatic trans-urethral resection, and thus is potentially life threatening. Furthermore, the recurrence of gross intractable hematuria is a significant concern, worsening the quality of residual life. Thus, SRC with a palliative intent may be an effective treatment of choice.

Zebic et al. ${ }^{[25]}$ carried out seven SRCs with a palliative intent, namely the surgical indication was due to T4a bladder cancer ( 3 patients) and pelvic malignancies leading to severe voiding symptoms, pain, and hematuria with need for repeated blood transfusions. Among them, 3 patients were lost during follow-up, 2 patients died during recovery for complications, and 2 patients lived 366 days after surgery. The preoperative risk was assessed by ASA score, resulting 4 patients ASA 4, two ASA 2, and one ASA 1.

Nagele et al. ${ }^{[26]}$ investigated clinical outcomes of 20 patients, with a mean age of 64 years, undergoing SRC for T4-stage bladder cancer. After a mean follow-up of 13 months (range 1-36 months), 11 patients were still alive. The authors reported only one lethal complication, namely an enterocutaneous fistula occurring during recovery. No data on preoperative surgical risk were reported.

The study of Cochetti et al. ${ }^{[27]}$ included 12 patients who underwent RC for massive hematuria due to bladder cancer and causing severe anemia ( $\mathrm{Hb}$ level $<8 \mathrm{~g} / \mathrm{dL}$ ). The pathological exam showed pT4 stage in 6 patients, 2 patients with $\mathrm{pT} 2$, and 4 patients affected by $\mathrm{pT} 3$ stage disease. Major complications occurred in $18.5 \%$ of cases, while no deaths were recorded. Although all patients were defined as ASA 4, the mean Charlson Index was 6 and median Karnofsky scale was 85. An ileal conduit was used as a urinary diversion in all studies mentioned above, while ureterocutaneostomy was performed in the presence of severe comorbidities and poor performance status.

Thus, the studies all showed that, if technically feasible, in patients with a decent frailty status and accepting surgery, the future problems of bleeding may be completely obviated. Frailty is a new concept introduced to 
estimate the patient's vulnerability to stress factors such as surgery. It has been recently developed in the context of bladder cancer because of the patient's median age at diagnosis, which makes the presence of several comorbidities highly probable ${ }^{[28]}$. Although a variety of methods are available to measure frailty, a poor score has usually been associated with worse postoperative outcomes in patients who undergo urologic surgery including $\mathrm{RC}^{[28]}$.

When SRC is not possible due to the patient's elevated frailty status or the patient's refusal, several alternatives to a radical treatment have been proposed.

Since 1960, low-dose RT has been adopted to control hematuria. Regarding treatment outcomes, at 2 weeks, the rate of efficacy in arresting bladder bleedings has been reported as 60\%-69\%, while the risk of recurrence at 6 months has been computed as $33 \%-69 \%^{[29-31]}$.

Selective angiography for bladder embolization showed a high success rate (82\%-100\%) with complete cessation of hematuria within $48 \mathrm{~h}$ and a bleeding recurrence risk of $28 \%-50 \%$ within 16 months ${ }^{[32]}$. However, this option is not free from complications. Ischemic pain, bladder necrosis, bladder infarction, and even inadvertent occlusion of uninvolved vessels by refluxed embolic material have been reported ${ }^{[33]}$.

Finally, several endovesical agents have been used to stop bladder bleeding such as $1 \%$ silver nitrate or 1\%$2 \%$ alum and formalin (2.5\%-4\% for $30 \mathrm{~min}$ ) with response rates of $71 \%-100 \%$ and $5 \%-100 \%$, respectively. However, the treatment lasted 1-5 days, and in all cases anesthesia was required.

\section{Salvage radical cystectomy: morbidity and mortality}

$\mathrm{SRC}$ is thought to be difficult because of previous radiotherapy. Pelvic RT results in tissue damage that can also affect surrounding organs and lead to desmoplastic reaction, obliterating the tissue plane. This makes it difficult to identify and dissect surgical structures ${ }^{[34]}$.

By researching studies only using Clavien-Dindo system to grade complications, we found three singleinstitution studies ${ }^{[5,35,36]}$ which assessed complications of SRC after RT for MIBC and one multicenter study $^{[37]}$ where SRC was carried out after RT for further diseases [Tables 3 and 4].

Gontero et al. ${ }^{[37]}$ retrospectively analyzed data from 25 large-volume institutions, defined as more than 30 cystectomies per year. Although only $27 \%$ of patients previously received RT for bladder cancer, the authors showed that the SRC is associated with a high risk of morbidity (75\% risk of a single complication and a 33\% risk of a major complication) and a 3.1\% mortality rate at 90 days after surgery. Only large-volume centers participated in this study. Surgeon volume had a greater impact on outcomes in RC when compared with other surgeries such as lung resection for cancer, abdominal aortic aneurysm repair, and coronary artery bypass $^{[38]}$. Furthermore, it has been computed that more than 20 RCs per year positively affected the complication rates when compared to a lower number ${ }^{[39]}$.

Iwai et al. ${ }^{[35]}$ compared complication rates in patients with and without previous TMT using the standardized Clavien-Dindo grade. Data analysis showed that previous chemoradiotherapy increases the risk of urinary anastomosis-related complications (such as stricture and urinary leakage) and is associated with gastrointestinal complications (such as bowel perforation and Grade 3 ileus). 
Table 3. Studies on complications after salvage radical cystectomy

\begin{tabular}{|c|c|c|}
\hline Ref. & $\begin{array}{l}N \text { of patients } \\
\text { undergone to SRC }\end{array}$ & Findings \\
\hline Iwai et al. ${ }^{[35]}$ & 87 & $\begin{array}{l}40 \text { Gy administered. Retrospective in nature comparing } 87 \text { SRC vs. } 106 \text { RC } \\
\text { Urinary anastomosis-related complications and major gastrointestinal complications, most of } \\
\text { which were Grade } 3 \text { ileus, were more frequent in the SRC respectively: } 11 \% \text { vs. } 2 \%, P=0.007 \\
\text { and } 14 \% \text { vs. } 4 \%, P=0.002\end{array}$ \\
\hline Eswara et al. ${ }^{[5]}$ & 91 & $\begin{array}{l}\text { Induction RT dose } 40 \mathrm{~Gy}+25 \text { Gy consolidation in case of positive initial response } \\
\text { Major complications, CCS } \geq 3 \text {, occurred in } 15 \text { patients }(16 \%) \text {. The overall } 90 \text {-day complication } \\
\text { rate was } 69 \% \text {. Perioperative mortality rate within } 90 \text { days was } 2.2 \%\end{array}$ \\
\hline Eisenberg et al. ${ }^{[36]}$ & 148 & $\begin{array}{l}\text { Radiotherapy by } 70 \text { Gy. } 90 \text {-day overall complication rate was } 77 \% \text {. Among them, } 44.6 \% \text { were } \\
\text { low grade and } 32.4 \% \text { high-grade. The type of urinary diversion was not related to complication } \\
\text { occurence }\end{array}$ \\
\hline Gontero et al. ${ }^{[37]}$ & 682 & $\begin{array}{l}\text { Retrospective in nature from SRCs carried out in } 25 \text { high volume centers (more than } 30 \\
\text { procedures per year). Overall rate of complications was } 75.1 \% \text {; CCS } \geq 3 \text { in } 29.6 \% \text { and CCS }=5 \\
\text { in } 2.9 \% \text { of patients. } 27 \% \text { of patients received RT for bladder cancer. Mean RT dose was } 63 \text { Gy } \\
(51-70)\end{array}$ \\
\hline
\end{tabular}

RC: Radical cystectomy; SRC: salvage radical cystectomy; RT: radiotherapy; CCS: Clavien Classification System.

Table 4. Reported range of complications graded by Clavien-Dindo System

\begin{tabular}{lll}
\hline & Grade $\geq \mathbf{3}$ & Grade $<3$ \\
\hline Infection (wound, urinary tract, others) & $3-7$ & $4-43$ \\
Gastrointestinal (ileus, bowel perforation) & $8-14$ & $10-17$ \\
Urinary anastomosis-related (leakage, stricture) & $2-5$ & $3-7$ \\
\hline
\end{tabular}

According to the authors, these complications would result, at least in part, from compromised blood supply to the tissue because of previous RT. Most patients (84\%) received an ileal conduit as a urinary diversion, while the others received orthotopic ileal neobladder (6\%), Indiana pouch (3\%), or ureterocutaneostomy $(7 \%)$. When univariate analysis was carried out to identify risk factors associated with urinary and bowel complications, the type of urinary diversions was not a predictor.

Eisenberg et al. ${ }^{[36]}$ reviewed clinical data of RCs performed in their tertiary referral care center. In 148 patients who underwent SRC, they computed a $32.4 \%$ rate of high-grade complications (CCS $\geq 3$ ). Again, ileal conduit was the most used urinary diversion (43.9\%), and this was not related to the occurrence of complications, while ASA score and patients age were predictors.

Finally, in the study by Eswara et al. ${ }^{[5]}$, which included 192 SRCs, major complications, Grades 3-5, occurred in 15 patients $(16 \%)$ for a total of 23 events. The perioperative mortality rate within 90 days was $2.2 \%$. Ileal conduit was the only used urinary diversion. However, the main finding of their study was to stratify complications occurrence by the date of SRC. Although there were no significant differences in the number of total complications, tissue healing-related complications occurred nearly three times more frequently ( $35 \%$ vs. $12 \%, P=0.05$ ) in the case of late SRC, namely disease recurrence after a mean of 10.3 months (range 2.1-178 months) from TMT termination. This group of complications included wound infection, ureteral stricture, anastomotic stricture, and stoma/loop requiring revision. Again, the authors explained this finding by assuming the higher dose (mean $64.7 \mathrm{~Gy} v$ s. $39.9 \mathrm{~Gy}$ ) of radiation received.

All these studies reported occurrence of urinary anastomosis-related complications and major gastrointestinal complications more likely in the case of a previous radiotherapy that presumably caused an endarteritis process with subsequent ischemia delaying wound healing ${ }^{[40]}$. 


\section{CONCLUSION}

Salvage radical cystectomy is performed both after failure of conservative treatment for muscle invasive bladder cancer and as a palliative surgery in the case of intractable and fatal complications such as hematuria. An appropriate selection of patients suited for TMT leads to acceptable outcomes, whereas the rate of major complications ( $C C S \geq 3$ ) in the case of a subsequent SRC is higher than the one previously reported for $\mathrm{RC}^{[41]}$. Furthermore, during patient counseling for TMT, the high probability of receiving an incontinent urinary diversion in the future instead of an orthotopic neobladder in the case of immediate RC should be underlined. In the absence of comparative studies able to identify risk factors for TMT failure, a multidisciplinary cooperation and close follow-up is required. Likewise, SRC for symptom relief should be considered only if there are no other options and after an accurate assessment of patient frailty through the currently available questionnaires such as ASA score Charlson Index, Karnofsky scale, and Geriatric-8 currently able to estimate patient's vulnerability to stress factors such as surgery.

\section{DECLARATIONS}

\section{Authors' contributions}

Data research and manuscript drafting: Cicione A, Lombardo R, Voglino OA

Manuscript revision: Tubaro A, De Nunzio C

\section{Availability of data and materials}

Not applicable.

\section{Financial support and sponsorship}

None.

\section{Conflicts of interest}

All authors declared that there are no conflicts of interest.

\section{Ethical approval and consent to participate}

Not applicable.

\section{Consent for publication}

Not applicable.

\section{Copyright}

(c) The Author(s) 2021.

\section{REFERENCES}

1. Cicione A, De Nunzio C, Lombardo R, et al. Complications and quality of life of ileal conduit, orthotopic neobladder and ureterocutaneostomy: systematic review of reports using the Clavien-Dindo Classification. Minerva Urol Nefrol 2020;72:408-19. DOI PubMed

2. Alfred WJ, Lebret T, Comperat EM, et al. Updated 2016 EAU Guidelines on muscle-invasive and metastatic bladder cancer. Eur Urol 2017;71:462-75. DOI PubMed

3. Mitropoulos D, Artibani W, Graefen M, et al. Reporting and grading of complications after urologic surgical procedures: An ad hoc EAU Guidelines Panel Assessment and Recommendations. Eur Urol 2012;61:341-9. DOI PubMed

4. Moher D, Liberati A, Tetzlaff J, Altman DG. Preferred reporting items for systematic reviews and meta-analyses: the PRISMA statement. BMJ 2009;339:b2535. DOI PubMed PMC

5. Eswara JR, Efstathiou JA, Heney NM, et al. Complications and long-term results of salvage cystectomy after failed bladder sparing therapy for muscle invasive bladder cancer. J Urol 2012;187:463-8. DOI PubMed

6. George L, Bladou F, Bardou VJ, et al. Clinical outcome in patients with locally advanced bladder carcinoma treated with conservative multimodality therapy. Urology 2004;64:488-93. DOI PubMed

7. Linell O. Salvage cystectomy. Review of 19 cases. Eur Urol 1987;13:17-21. DOI PubMed

8. Konnak JW, Barton Grossman H. Salvage cystectomy following failed definitive radiation therapy for transitional cell carcinoma of 
bladder. Urology 1985;26:550-3. DOI PubMed

9. Smith JA, Whitmore WF. Salvage cystectomy for bladder cancer after failure of definitive irradiation. J Urol 1981;125:643-5. DOI PubMed

10. Kulkarni GS, Hermanns T, Wei Y, et al. Propensity score analysis of radical cystectomy versus bladder-sparing trimodal therapy in the setting of a multidisciplinary bladder cancer clinic. J Clin Oncol 2017;35:2299-305. DOI PubMed

11. Cooke PW, Dunn JA, Latief T, Bathers S, James ND, Wallace DMA. Long-term risk of salvage cystectomy after radiotherapy for muscle-invasive bladder cancer. Eur Urol 2000;38:279-86. DOI PubMed

12. Nieuwenhuijzen JA, Horenblas S, Meinhardt W, Van Tinteren H, Moonen LMF. Salvage cystectomy after failure of interstitial radiotherapy and external beam radiotherapy for bladder cancer. BJU Int 2004;94:793-7. DOI PubMed

13. Bochner BH, Figueroa AJ, Skinner EC, et al. Salvage radical cystoprostatectomy and orthotopic urinary diversion following radiation failure. J Urol 1998;160:29-33. DOI PubMed

14. Crawford ED, Skinner DG. Salvage cystectomy after irradiation failure. J Urol 1980;123:32-4. DOI PubMed

15. Freiha FS, Faysal MH. Salvage cystectomy. Urology 1983;22:496-8. DOI PubMed

16. Swanson DA, von Eschenbach AC, Bracken RB, Johnson DE. Salvage cystectomy for bladder carcinoma. Cancer 1981;47:2275-9. DOI PubMed

17. Abratt RP, Wilson JA, Pontin AR, Barnes RD. Salvage cystectomy after radical irradiation for bladder cancer-prognostic factors and complications. Br J Urol 1993;72:756-60. DOI PubMed

18. Nurmi M, Valavaara R, Puntala P, Ekfors T. Single-stage salvage cystectomy: results and complications in 20 patients. Eur Urol 1989;16:89-91. DOI PubMed

19. Rödel C, Grabenbauer GG, Kühn R, et al. Organ preservation in patients with invasive bladder cancer: Initial results of an intensified protocol of transurethral surgery and radiation therapy plus concurrent cisplatin and 5-fluorouracil. Int J Radiat Oncol Biol Phys 2002;52:1303-9. DOI PubMed

20. Polo-Alonso E, Kuk C, Guruli G, et al. Trimodal therapy in muscle invasive bladder cancer management. Minerva Urol Nefrol 2020;72:650-62. DOI PubMed

21. Mak RH, Hunt D, Shipley WU, et al. Long-term outcomes in patients with muscle-invasive bladder cancer after selective bladderpreserving combined-modality therapy: a pooled analysis of radiation therapy oncology group protocols 8802, 8903, 9506, 9706, 9906, and 0233. J Clin Oncol 2014;32:3801-9. DOI PubMed PMC

22. Schuettfort VM, Pradere B, Quhal F, et al. Incidence and outcome of salvage cystectomy after bladder sparing therapy for muscle invasive bladder cancer: a systematic review and meta-analysis. World J Urol 2020. DOI PubMed

23. Stein JP, Lieskovsky G, Cote R, et al. Radical cystectomy in the treatment of invasive bladder cancer: long-term results in 1,054 patients. J Clin Oncol 2001;19:666-75. DOI PubMed

24. Martini A, Sfakianos JP, Renström-Koskela L, et al. The natural history of untreated muscle-invasive bladder cancer. BJU Int 2020;125:270-5. DOI PubMed

25. Zebic N, Weinknecht S, Kroepfl D. Radical cystectomy in patients aged $\geq 75$ years: an updated review of patients treated with curative and palliative intent. BJU Int 2005;95:1211-4. DOI PubMed

26. Nagele U, Anastasiadis AG, Merseburger AS, et al. The rationale for radical cystectomy as primary therapy for T4 bladder cancer. World J Urol 2007;25:401-5. DOI PubMed

27. Cochetti G, Barillaro F, Boni A, Mearini E. Immediate radical cystectomy for massive bleeding of bladder cancer. Biomed Res Int 2015;2015:154392. DOI PubMed PMC

28. De Nunzio C, Cicione A, Izquierdo L, et al. Multicenter analysis of postoperative complications in octogenarians after radical cystectomy and ureterocutaneostomy: the role of the frailty index. Clin Genitourin Cancer 2019;17:402-7. DOI PubMed

29. Lacarrière E, Smaali C, Benyoucef A, Pfister C, Grise P. The efficacy of hemostatic radiotherapy for bladder cancer-related hematuria in patients unfit for surgery. Int Braz J Urol 2013;39:808-16. DOI PubMed

30. Wujanto C, Tey J, Chia D, et al. Radical radiotherapy in older patients with muscle invasive bladder cancer. J Geriatr Oncol 2019;10:292-7. DOI PubMed

31. Abt D, Bywater M, Engeler DS, Schmid HP. Therapeutic options for intractable hematuria in advanced bladder cancer. Int J Urol 2013;20:651-60. DOI PubMed

32. Loffroy R, Pottecher P, Cherblanc V, et al. Current role of transcatheter arterial embolization for bladder and prostate hemorrhage. Diagn Interv Imaging 2014;95:1027-34. DOI PubMed

33. Mohan S, Kumar S, Dubey D, Phadke RV, Baijal SS, Kathuria M. Superselective vesical artery embolization in the management of intractable hematuria secondary to hemorrhagic cystitis. World J Urol 2019;37:2175-82. DOI PubMed

34. Ramani VAC, Maddineni SB, Grey BR, Clarke NW. Differential complication rates following radical cystectomy in the irradiated and nonirradiated pelvis. Eur Urol 2010;57:1058-63. DOI PubMed

35. Iwai A, Koga F, Fujii Y, et al. Perioperative complications of radical cystectomy after induction chemoradiotherapy in bladder-sparing protocol against muscle-invasive bladder cancer: a single institutional retrospective comparative study with primary radical cystectomy. Jpn J Clin Oncol 2011;41:1373-9. DOI PubMed

36. Eisenberg MS, Dorin RP, Bartsch G, Cai J, Miranda G, Skinner EC. Early complications of cystectomy after high dose pelvic radiation. J Urol 2010;184:2264-9. DOI PubMed

37. Gontero P, Pisano F, Palou J, et al. Complication rate after cystectomy following pelvic radiotherapy: an international, multicenter, retrospective series of 682 cases. World J Urol 2020;38:1959-68. DOI PubMed

38. Birkmeyer JD, Stukel TA, Siewers AE, Goodney PP, Wennberg DE, Lucas FL. Surgeon volume and operative mortality in the United 
States. N Engl J Med 2003;349:2117-27. DOI PubMed

39. Nielsen ME, Mallin K, Weaver MA, et al. Association of hospital volume with conditional 90-day mortality after cystectomy: an analysis of the National Cancer Data Base. BJU Int 2014;114:46-55. DOI PubMed PMC

40. Mak RH, Zietman AL, Heney NM, Kaufman DS, Shipley WU. Bladder preservation: Optimizing radiotherapy and integrated treatment strategies. BJU Int 2008;102:1345-53. DOI PubMed

41. De Nunzio C, Cindolo L, Leonardo C, et al. Analysis of radical cystectomy and urinary diversion complications with the Clavien classification system in an Italian real life cohort. Eur J Surg Oncol 2013;39:792-8. DOI PubMed 